\title{
EUROPE 2020 SI-LAB: A New Center for Economic and Social Development in Sicily
}

\author{
Vincenzo Provenzano ${ }^{1, a}$, Maurizio Carta ${ }^{1, b}$ and Massimo Arnone $e^{1, c}$ \\ ${ }^{1}$ University of Palermo and SI-LAB, Italy \\ avincenzo.provenzano@unipa.it, ${ }^{b}$ maurizio.carta@unipa.it ${ }^{c}$ massimo.arnone@unipa.it
}

Keywords: SI-LAB, Europe 2020, Local Development, Governance, Regional Innovation Systems.

\begin{abstract}
The debate on the determinants of regional and local development has been stimulated recently by the European strategy for smart, sustainable and inclusive growth defined as Europe 2020 . We present the objectives and structure of a new laboratory (SI-LAB) for the development of Sicilian economy promoted by the University of Palermo. In particular, we highlight the fundamental issues related to the incoming functioning of the Lab as a new oganization devoted to analyzing public policy issues, and fostering new ways of entrepreurship at the local level.
\end{abstract}

\section{Introduction}

The European strategy for smart, sustainable and inclusive growth - Europe 2020- gave greater vitality to the debate on local development that has been debated in Italy in the last two decades, and focused attention on some necessary to promote a more stable development of our enterprise system.

There is a large number of studies describing the role of development driving forces such as the integration of production, the openness to international markets, the importance of asset knowledge in the process of technology transfer, as well as the emergence of a "Business University or Third University "(Piccaluga, 2003) [1]. Furthermore, the socio-economic development is the result of a more important role of institutions in the new policy guidelines via the creation of a relational space favorable to knowledge and innovation. Following the financial crisis of 2007, new possibilities are open for all development factors previously mentioned, but embedded in a more unstable and dynamic framework .

The firms, especially those of small and medium size must be able to respond quickly to a different competitive environment, which threatens the survival for all types of activities (including the most standardized) and requiring the dissemination of innovation trough shorter lifecycles / technological trajectories with a deeper cost and risk dimensions.

In this context, the linear type management process of innovation- technology push- based on the central concept of research and development has become less important whereas the managerial conceptions of systemic and procedural innovation are more important.

The systemic view of innovation has outlined the following key factors to explain the genesis and the success of any local system of innovation (Nelson and Winter (1993) [2], Teece and Pisano (1994) [3]): the primacy of small and medium-sized firms, the radical nature of innovation projects and the greater variability and flexibility of smal firms compared to large ones .

Several contributions (Lundwall (1992) [4], Nelson et al. (1993) [5], Cooke (1998) [6], Andersson and Karlsson (2004) [7]) have fueled the debate on innovation systems. Furthermore, the recent literature identified other key factors: the presence of district external economies, the social dimension expressed by the relations of cooperation together with the centrality of processes interactive learning.

According to our perspective, Braczyk, Cooke and Heidenreich (1998) [8] propose a classification of regional innovation systems focused on the presence of specific governance models of technology transfer processes defined respectively grassroots, networks, and hierarchical systems. 
The grassroots process type indicates simplified ways of innovation at the local level, the network procedure considers an interconnected horizontal and vertical transfer process whereas the third one is centralized following a top down process. In this regard, the SI-LAB aims to encourage a networking governance process for regional public and private innovation activities developed in the next paragraph.

\section{The basic architecture of the SI-LAB}

The University of Palermo has entitled the SI-LAB in honor of Alberto Tulumello and his ideas about the social market construction establishing "a center for innovation and entrepreneurship to create an environment that will assist in identifying and sustaining local entrepreneurs as a way of stimulating locally based economic development throughout the Mediterranean basin“ [9].

The laboratory aims to foster a multilevel and participatory governance to develop the region of Sicily, hampered by long-standing structural weakness. The structure includes both the creation of public-private partnerships, and cooperation between the various hierarchical levels of government, to ensure the achievement of the consistency of the different levels of public interventions in terms of design, management and final evaluation.

The university becomes a positive actor and active stakeholder to reduce the development gap between the South and the North of Italy, promoting a more intense dialogue between the supply of knowledge and the local demand for it, capable to manage local development trajectories, This quantum leap in the way of understanding the management of local development processes is necessary to give more validity to the literature on innovation systems (national and regional) that revolves around the model of the triple helix.

The SILAB has identified six fundamental areas that deserve assistance such as : a) to promote active ways for knowledge / skills transfer b) creation of a system of international cooperation, research and integration within the framework of the Mediterranean Basin, c) stimulating the realization of studies, research, structural analysis and diagnosis of scenarios d) the development of the 2014-2010 action plan set by the European Commission e) Enhancing the endogenous resources, promote economic and social welfare, security and opportunities for the local communities, f) Support training through the organization of Masters programs, Summer and Winter Schools.

According to all ambitious objectives, the SI-LAB underlines some research areas such: a) Critical reading of current policies and analysis of prospective regional solutions for public intervention in Sicily, b) evaluation past development practices activated with public policies over the past few years, c) comparative analysis of experiences development / best practices activated in other regions of Italy to become aware of the opportunities to be seized at the local level, d) structural observation of territorial, economic and social scenarios, inside the European market scenario, in order to enable a better listening of local actors (sensors) and their specific needs.

The development of alternative regional development scenarios with shared objectives will be specified in detail in "Green Paper" report that will be submitted to the main institutional players.

The seven thematic tables concern the following macro-7 thematic areas indicating strategic themes of the laboratory: 1) Governance and institutions, 2) Education and research, 3) Quality of the territory and cohesion, 4) Economic activity and growth, 5 ) Welfare and social inclusion, 6) Environment and energy, 7) Taxation and finance. (see figure 1) 


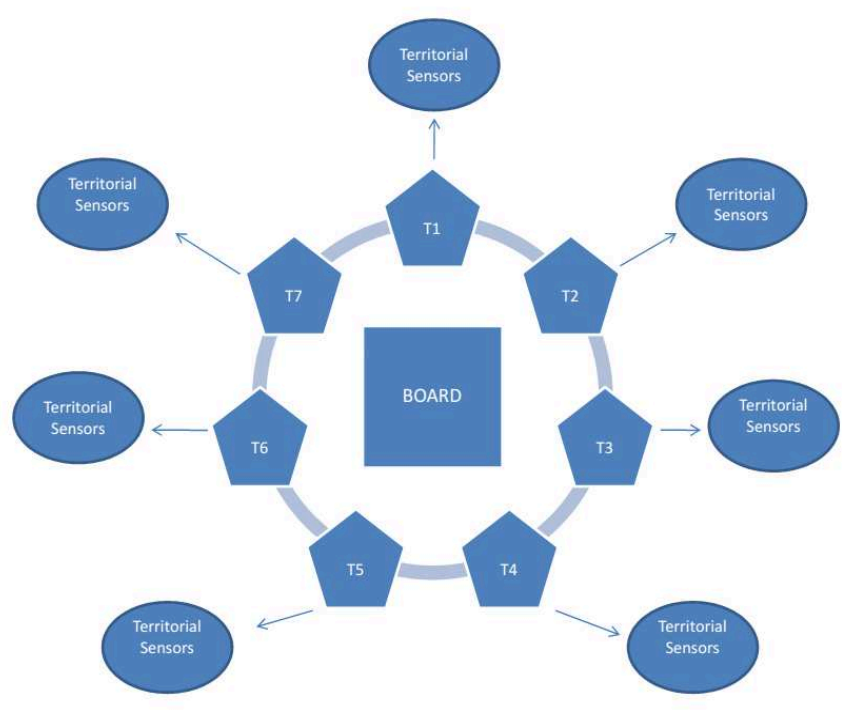

Fig. 1 : The SI-LAB structure

LEGEND: T1: Thematic tabel "Governance and Institutions", T2: Thematic tabel "Education and research", T3: Thematic tabel "Quality territory and cohesion", T4: Thematic tabel "Economic activity and growth", T5: Thematic tabel "Welfare and Social Inclusion", T6: Thematic tabel "Environment and energy", T7: Thematic tabel "Taxation and Finance"

With regards to the network of actors involved within each thematic table, first, there is a coordinator that convenes the table to develop and aggregate sector analysis. Each table consists of a number of internal and external experts at the University of Palermo. The members of each thematic table are elected by the Coordination Table, a majority of those entitled to vote. On the proposal of the coordinator or at the request of at least half of the members may be invited other experts, internal or external expertise consistent with the content of the carried out analyses.

The procedure for the preparation of this document can be divided into the following phases: 1) The Coordination Table invites the seven thematic groups to initiate a discussion on issues of significance to the definition of developmental trajectories of Sicily, 2)The Thematic tables show the results of the meeting of summaries, 3)The drafts are then sent to the members of the Coordination Table, 4)The Coordination Table selects the most relevant topics and exploiting the formulated results processes addresses economic planning to start a circuit development in the region;, 5)The document processing sector leads to the development of the Green Paper which has as its object the diagnosis of regional policies and local development.

For example, the thematic tables "Welfare and Social Inclusion ", "education and research" could formulate policy guidance useful to significantly reduce the development gaps in Sicily against the objectives of the target Eurooa 2020. These differences reached dimensions rathe worrying with reference to the labor market (with an occupancy rate of less than 22 percentage points), the quality of the primary education system (with a lower rate of primary education by 10 percentage points). As for university education in the high-tech disciplines there are no significant differences between the regions of southern Italy compared with the target of Europe 2020 (although they are always regions of Sicily and Campania, with a population in possession of a know-how in technological disciplines lower ). This delay in the formation of a set of skills in high-tech sectors can be considered one of the causes of the failure of industrial policies designed to boost the technological districts in Sicily.

With reference to the problems of poverty and social exclusion, Sicily has the highest poverty rate among the regions of the Mezzogiorno (equal to 55 percent of the entire population), even if in 2012 all the southern regions have a higher rate of poverty by more than 30 percent compared to the objectives of Europe 2020 [10]. 
The SI-LAB with the involvement of university departments can promote research projects that are supported by EU, national and local funds in collaboration with other public and private entities. The assessment of project viability is attributed to the coordination table that holds the project's consistency with the nature and purpose of the activity carried out by the SI-LAB, its organizational and financial sustainability and goodness in terms of expected results.

For all projects (both internal and external), the SI-LAB tends to align the structure of each research project the following aspects: a) monitoring of the operational phases of project development, field visits and collection of information and data, $b$ ) verification to the effectiveness of the final results and the impact on beneficiaries, c) verification of real use and consistent allocation of resources. The SI-LAB can also take decisions regarding the management of financial resources obtained through the University to ensure effective financial support to research and development in the context of: a) conducting research projects, b ) the activities of third parties, c) agreements signed by other universities and university departments, d) transfers from other universities and university departments, e) donations and / or grants from public and private entities. All received funds are managed through the Administration of the University which will identify, by the Director General, the center of administrative responsibility.

\section{The Spin-off activity of SI-LAB: a realistic outcome?}

In recent years, the Northern regions of Italy have registered a high percentages of concentration of Italian spin-off, (see table 1, Piccaluga 2012), and in the past a vision extremely optimistic about the growth dynamics of firms derived from spin-off has been established. It seems difficult to deny that those firms are able to grow much faster than those operating in traditional sectors. (Cooper et al., 1986) [12]

However, this optimism proved unsuccessful, especially in the last decade. Several empirical studies have shown, that the majority of high tech companies, including those born through a spin-off research process, has grown slowly. It seems realistic to underline that some spin-off firms are the outome of a specific entrepreneurial initiatives with the involvement of industrial and financial partners.

Table 1: Geographical location of spin-off $(n=110)$, Source Piccaluga (2013)

\begin{tabular}{|l|c|c|c|c|c|c|c|c|c|c|}
\hline $\begin{array}{l}\text { Region / Year } \\
\text { of establishment }\end{array}$ & $\begin{array}{c}\text { Before } \\
1997\end{array}$ & $\%$ & $98-02$ & $\%$ & $03-07$ & $\%$ & $08-12$ & $\%$ & 2013 & Total \\
\hline Lombardy & 5 & 14,7 & 16 & 13,0 & 50 & 12,3 & 54 & 10,1 & 0 & 125 \\
\hline Piedmont & 0 & 0,0 & 16 & 13.0 & 41 & 10,1 & 41 & 7,7 & 0 & 98 \\
\hline Liguria & 10 & 29,4 & 29 & 23,6 & 3 & 0,7 & 21 & 3,9 & 0 & 63 \\
\hline Emilia Romagna & 0 & 0,0 & 18 & 14,6 & 54 & 13,3 & 25 & 4,7 & 0 & 97 \\
\hline Friuli Venezia Giulia & 1 & 2,9 & 5 & 4,1 & 25 & 6,2 & 20 & 3,8 & 0 & 51 \\
\hline Veneto & 0 & 0,0 & 2 & 1,6 & 19 & 4,7 & 37 & 6,9 & 0 & 58 \\
\hline Trentino Alto Adige & 2 & 5,9 & 2 & 1,6 & 6 & 1,5 & 17 & 3,3 & 0 & 27 \\
\hline Tuscan & 9 & 26,5 & 17 & 12,2 & 39 & 9,6 & 47 & 8,8 & 3 & 113 \\
\hline Lazio & 3 & 8,8 & 7 & 5,7 & 55 & 13,5 & 77 & 14,4 & 0 & 142 \\
\hline Marche & 0 & 0,0 & 4 & 3,3 & 19 & 4,7 & 27 & 5,1 & 0 & 50 \\
\hline Umbria & 0 & 0,0 & 0 & 0,0 & 19 & 4,7 & 13 & 2,4 & 0 & 32 \\
\hline Abruzzo & 0 & 0,0 & 0 & 0,0 & 9 & 2,2 & 7 & 1,3 & 0 & 16 \\
\hline Puglia & 1 & 2,9 & 2 & 1,6 & 19 & 4,7 & 60 & 11,3 & 6 & 88 \\
\hline Sardinia & 1 & 2,9 & 1 & 0,8 & 16 & 3,9 & 22 & 4,1 & 0 & 40 \\
\hline Calabria & 1 & 2,9 & 4 & 3,3 & 10 & 2,5 & 13 & 2,4 & 0 & 28 \\
\hline Campania & 0 & 0,0 & 0 & 0,0 & 10 & 2,5 & 27 & 5,1 & 0 & 37 \\
\hline Sicily & 1 & 2,9 & 1 & 0,8 & 11 & 2,7 & 16 & 3,0 & 0 & 29 \\
\hline Basilicata & 0 & 0,0 & 0 & 0,0 & 0 & 0,0 & 2 & 0,4 & 0 & 2 \\
\hline Molise & 0 & 0,0 & 1 & 0,8 & 1 & 0,2 & 7 & 1,3 & 0 & 9 \\
\hline Total to 22 May 2013 & 34 & 100,00 & 123 & 100,00 & 406 & 100,00 & 533 & 100,00 & 9 & 1105 \\
\hline
\end{tabular}


In this direction the SI-LAB could help to overcome a series of obstacles to develop and maintain a spin-off process, related, for example, to new forms of regional innovation systems i.e. technological districts.

The development of policies for successful policy innovation requires the presence of a greater role of local institutions. The knowledge-based innovation is not considered the only lever of development as part of the operating logic and the thematic objectives of the SI-LAB. These instruments do not always lead to the desired results because they are not placed in a cooperative that can involve actors and and not just firms. In other words, these instruments for innovation and, more generally, policies for local development should be placed in the context of evolutionary economic geography "that not only has as its objective the development of scientific knowledge.

The SI-LAB could fulfill the role of the steering committee responsible for the governance of an integrated development and participated in the Sicilian economy.

The research and development, marked by greater uncertainty, more time, costs and higher risks, needs for its support, to reach a critical mass of resources, knowledge and skills especially for the benefit of SMEs. The SI-LAB could facilitate the achievement of this goal by encouraging greater development of the Sicilian economy.

The SI-LAB, after a careful analysis of the area, may also schedule among its lines of action, the realization of investments from top to relaunch the technological districts in our region, thus reducing the gap with other Italian and European regions.

Recalling the model of the Triple Helix Etzkovitz et al. (2000) [13] aims to explain the genesis of any district technology, the SI-LAB could serve as a link between the three helices identified in the three main actors located in the territory served by the district namely political institutions, universities and firms, thus fueling a virtuous circle of social capital for the benefit of the whole territory. Therefore, the SI-LAB is an open network of applied research.

\section{Conclusions}

The approach of the local systems of innovation has shown that innovation is an evolutionary, non-linear and interactive activity that requires intensive communication and cooperation between enterprises and other organizations such as universities, public research institutes, centers of research, educational and financial institutions, regulatory bodies, industry associations and government agencies "and that this process is influenced positively by the formal and informal institutions active at the local level.

The SI-LAB aims to promote this process of innovation management in order to reduce the Sicilian development gaps with respect to the objectives of Europe 2020. The SI-LAB assuming the role of catalyst among universities and territorial sensors such as businesses and local institutions may become a trigger for innovation firms and new ways of entrepreurship.

This paper has highlighted some initial elements of SI-LAB and how can be useful for the Sicilian economy. If this young organization will succeed during the European strategy for smart, sustainable and inclusive growth several outcomes can be achieved such as:

a. the growth in terms of planning and "problem solving" of the local community

b. the ex ante evaluation of public policies expected impacts to support territorial innovation

c. the involvment of different levels of government

d. the development of a new concept of entrepreneuship for young talented and skilled people, a necessary ingredient to boost sustainable growth in Sicily where promising business processes are rather fragmented. 


\section{References}

[1] A. Piccaluga: Distretti tecnologici in Italia, esperienze attuali e prospettive, MIUR (2003)

[2] R. Nelson, S. Winter: An evolutionary theory of economic change. Cambridge: Harvard University Press (1993)

[3] D. Teece, G. Pisano: The dynamic capabilities of firms: an introduction. In: Industrial and Corporate Change, 3 (3), (1994), pp. 537-556

[4] B. A. Lundwall: Introduction. In: B. A. Lundwall, (ed.).1-9. National systems of innovation: towards a theory of innovation and interactive learning, London Pinter (1992)

[5] R. Nelson, N. Rosenberg: Technical innovation and national systems. In: R. Nelson (ed.): National innovation systems: a comparative analysis. Oxford University Press (1993)

[6] P. Cooke, M. G. Uranga, G. Etxebarria: Regional innovation systems: institutional and organizational dimensions. In: Research Policy, 26 (4), (1998), pp. 475-491

[7] M. Andersson, C. Karlsson: Regional innovation systems in small \& medium- sized regions. In: Paper No. 10, CESIS Working Paper, KTH Royal Institute of Technology (2004)

[8] H. J. Braczyk, P. Cooke, M. Heidenreich: Regional innovation systems. University College London Press (1998)

[9] A.W. Dyer, V. Provenzano: Creating and sustaining local entrepreneurs: a Schumpeterian view of economic growth, Proceedings of the 2010 EMUNI Research Souk 14 June (2010)

[10] European Commission Directorate-General Regional and Urban Policy Analysis Unit B1 (2013), Country Fact Sheet, July

[11] A. Piccaluga, F. Lazzeri: Le imprese spin-off della ricerca pubblica: convinzioni, realtà e prospettive future. In: Economia e Societa Regionale, (2012), pp.43-65

[12] A. C.Cooper, G. E. Willard, C. Y. Woo: Strategies of high performance new firms. In: Journal of Business Venturing, 1(3), (1986), pp. 247-260

[13] H. Etzkowitz, L. Leydesdorff: The dynamics of innovation: from national systems and mode 2 to a triple helix of university-industry-government Relations, Research Policy, 29, (2000) 